Check for updates

Cite this: RSC Adv., 2021, 11, 20118

Received 30th April 2021

Accepted 24th May 2021

DOI: 10.1039/d1ra03387e

rsc.li/rsc-advances

\section{Construction of cyclopentane-fused coumarins via DBU-catalyzed [3+2] cycloaddition of 3-homoacyl coumarins with cyclic 1-azadienes $\uparrow$}

\author{
Huawei Lin, ${ }^{a}$ Huimin Yang, ${ }^{a}$ Qi Gong, ${ }^{a}$ Shan Luo, ${ }^{a}$ Jing Gu, ${ }^{a}$ Xiaoqun Cao, ${ }^{a}$ \\ Biming Mao, ${ }^{* b}$ Yanqing Ge (D) *a and Chunhao Yuan (ID *a
}

The metal-free DBU catalyzed [3+2] cycloaddition of 3-homoacyl coumarins with cyclic 1-azadienes proceeded smoothly to furnish the corresponding highly functionalized cyclopentane-fused coumarins with excellent diastereoselectivity and complete chemoselectivity and in good yields under mild conditions.
Coumarins $\mathrm{s}^{1}$ and cyclopentane scaffolds ${ }^{2}$ are widely distributed in natural products and display a wide range of biological and pharmacological activities. When combining coumarin skeletons with cyclopentane moieties, the cyclopentane-fused coumarins show interesting biological activities. For example, aflatoxins, which occur naturally, exhibit acute toxicity, teratogenicity, mutagenicity and carcinogenicity (Fig. 1). ${ }^{3}$ Herbertenolide, which belongs to the family of sesquiterpenoids, was first isolated from the leafy liverwort Herberta adunca, the extract of which showed significant inhibition against the growth of certain plant pathogenic fungi (Fig. 1). ${ }^{4}$ Not surprisingly, the strategies for synthesis of cyclopentane-fused coumarins have attracted much attention. ${ }^{5}$

Recently, the group of Lin developed a 1,3-dipolar precursor 3-homoacyl coumarin, which is an efficient synthon for the

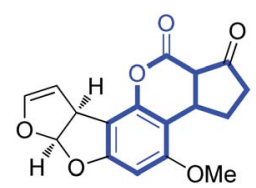

Aflatoxin B1

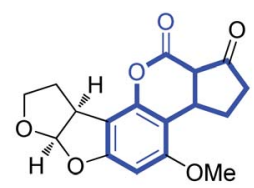

Aflatoxin B2

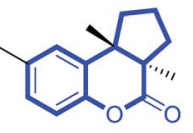

(-)-Herbertenolide
Fig. 1 Bioactive molecule bearing cyclopentane-fused coumarin.

${ }^{a}$ School of Chemistry and Pharmaceutical Engineering, Shandong First Medical University, Shandong Academy of Medical Sciences, Taian 271016, Shandong, P. R. China.E-mail: yuanchunhao2017@163.com; geyanqing2016@126.com

${ }^{b}$ Institute of Materia Medica, Shandong First Medical University, Shandong Academy of Medical Sciences, Jinan 250117, Shandong, P. R. China. E-mail: maobiming@ sdfmu.edu.cn

$\dagger$ Electronic supplementary information (ESI) available: Experimental conditions and spectroscopic data of all new compounds. CCDC 2073841. For ESI and crystallographic data in CIF or other electronic format see DOI: 10.1039/d1ra03387e construction of cyclopentane-fused coumarins under the catalysis of bases (Scheme 1a and b). ${ }^{6}$ However, the partners reacted with 3-homoacyl coumarins were focus on $\alpha, \beta$-unsaturated carbonyl compounds and conjugated dienes. The other dipolarophiles, such as aza-dienes, might also be potential candidates for the $[3+n]$ cycloadditions with 3-homoacyl coumarins but never been developed.

The cyclic 1-azadienes are extensive used dipolarophiles and have been widely involved in a series of cyclization reactions as two- ${ }^{7}$ three- ${ }^{8}$ or four ${ }^{9}$ member synthons. While the
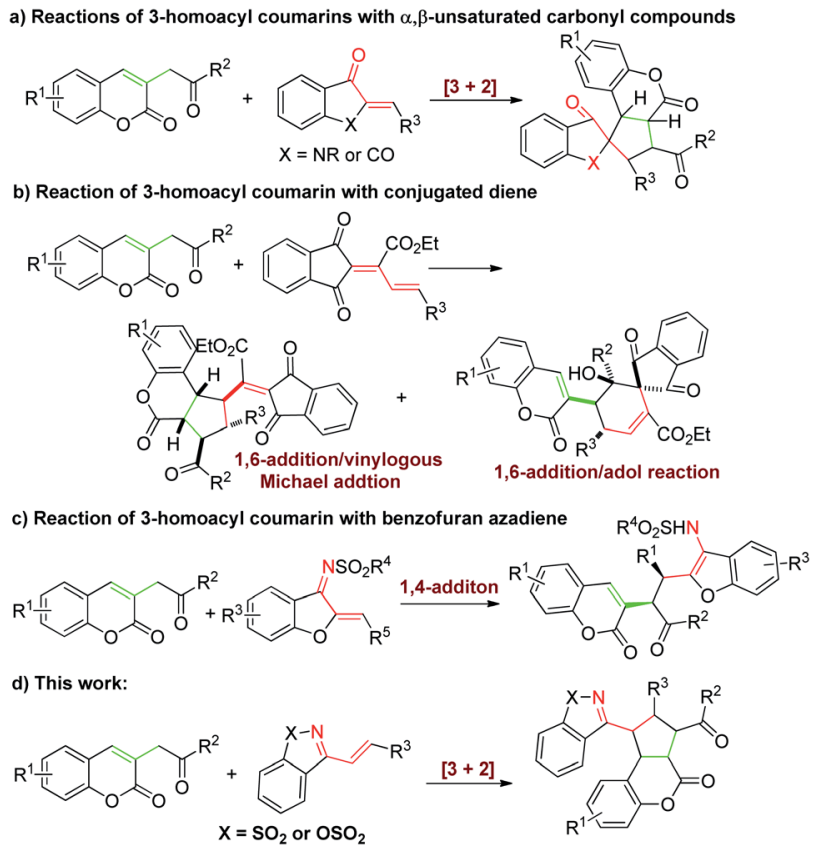

Scheme 1 The reaction of 3-homoacyl coumarins with dipolarophiles catalyzed by Brønsted base. 
organocatalytic [3+2] cycloaddition of cyclic 1-azadiene as two synthons has rarely been investigated. ${ }^{7 b, c}$ In 2016 , Chen' ${ }^{7 b}$ and Guo's ${ }^{7 c}$ group respectively developed a asymmetric [3+2] annulation reaction of Morita-Baylis-Hillman carbonates with cyclic 1-azadienes catalyzed by Lewis base. Encouraged by these works above and as our continuing efforts on cycloadditions,${ }^{10}$ herein we expected to achieve the first [3+2] cycloaddition reaction of 3-homoacyl coumarins with cyclic 1azadienes catalyzed by Brønsted base for synthesis of various functionalized cyclopentane-fused coumarins derivatives efficiently (Scheme 1d). However, Huang's group reported a enantioselective 1,4-addition reaction of benzofuran azadiene with 3-homoacyl coumarin, instead of cycloaddition (Scheme 1c). ${ }^{11}$ To achieve our assumption in high chemoselectivity would be a challenging work.

In an initial experiment, cyclic 1-azadiene 1a and 6-bromo-3(2-oxo-2-phenylethyl)-2H-chromen-2-one $2 \mathrm{a}$ were employed as the model substrates to carry out the reaction in $\mathrm{CH}_{2} \mathrm{Cl}_{2}$ at room temperature in the presence of DABCO. To our delight, the desired [3+2] cycloadduct 3aa was obtained in $56 \%$ yield (Table 1 , entry 1). Subsequently, several bases were screened and when the use of stronger base (Table 1, entries 2-4), DBU, the reaction gave a higher yield in $12 \mathrm{~h}$, and no 1,4-addition product was observed (Table 1, entry 3). Further screening of several representative solvents, such as THF, toluene, DCE and $\mathrm{CH}_{3} \mathrm{CN}$, revealed that the reaction proceeded better in THF with $86 \%$ yield (Table 1, entry 5). Therefore, the best reaction conditions were determined as below: DBU, THF and room temperature (Table 1, entry 5).

Under optimal reaction conditions, the substrate scope of the cyclic 1-azadienes 1 was investigated and the results were summarized in Table 2. As expected, the desired [3+2] cycloadducts $3 \mathbf{b a}-3 \mathbf{q a}$ were obtained in moderate to good

Table 1 Screening of the reaction conditions ${ }^{a}$

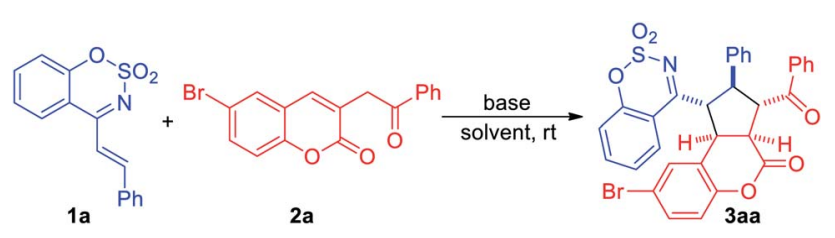

\begin{tabular}{|c|c|c|c|c|c|}
\hline Entry & Base & Solvent & Time (h) & Yield $^{b}(\%)$ & $\mathrm{dr}^{c}$ \\
\hline 1 & DABCO & $\mathrm{CH}_{2} \mathrm{Cl}_{2}$ & 24 & 56 & $>20: 1$ \\
\hline 2 & DMAP & $\mathrm{CH}_{2} \mathrm{Cl}_{2}$ & 24 & 60 & $>20: 1$ \\
\hline 3 & DBU & $\mathrm{CH}_{2} \mathrm{Cl}_{2}$ & 12 & 78 & $>20: 1$ \\
\hline 4 & $\mathrm{Et}_{3} \mathrm{~N}$ & $\mathrm{CH}_{2} \mathrm{Cl}_{2}$ & 24 & 67 & $>20: 1$ \\
\hline 5 & DBU & THF & 12 & 86 & $>20: 1$ \\
\hline 6 & DBU & Toluene & 12 & 31 & $>20: 1$ \\
\hline 7 & DBU & DCE & 12 & 76 & $>20: 1$ \\
\hline 8 & DBU & $\mathrm{CH}_{3} \mathrm{CN}$ & 12 & 73 & $>20: 1$ \\
\hline
\end{tabular}

${ }^{a}$ Reactions were carried out with $1 \mathrm{a}(0.1 \mathrm{mmol}), 2 \mathrm{a}(0.12 \mathrm{mmol})$, and base $(20 \mathrm{~mol} \%)$ in $2 \mathrm{~mL}$ of solvent at $\mathrm{rt} .{ }^{b}$ Isolated yields. ${ }^{c}$ Determined by ${ }^{1} \mathrm{H}$ NMR.
Table 2 Substrate scope of cyclic 1-azadienes $1^{a}$

\begin{tabular}{|c|c|c|c|c|}
\hline Entry & $\mathrm{R}^{1}$ in $\mathbf{1}$ & 3 & Yield $^{b}(\%)$ & $\mathrm{dr}^{c}$ \\
\hline & $2-\mathrm{FC}_{6} \mathrm{H}_{4}(\mathbf{1 b})$ & $3 \mathbf{b a}$ & 85 & $>20: 1$ \\
\hline & $3-\mathrm{FC}_{6} \mathrm{H}_{4}(1 \mathrm{c})$ & $3 \mathbf{c a}$ & 90 & $>20: 1$ \\
\hline & $4-\mathrm{FC}_{6} \mathrm{H}_{4}(\mathbf{1 d})$ & 3da & 85 & $>20: 1$ \\
\hline & $3-\mathrm{ClC}_{6} \mathrm{H}_{4}(\mathbf{1 e})$ & 3ea & 86 & $>20: 1$ \\
\hline & $4-\mathrm{ClC}_{6} \mathrm{H}_{4}(\mathbf{1 f})$ & $3 \mathrm{fa}$ & 80 & $>20: 1$ \\
\hline & $3-\mathrm{BrC}_{6} \mathrm{H}_{4}(\mathbf{1 g})$ & $3 g a$ & 79 & $>20: 1$ \\
\hline & $4-\mathrm{BrC}_{6} \mathrm{H}_{4}(\mathbf{1 h})$ & 3ha & 80 & $>20: 1$ \\
\hline & $4-\mathrm{CNC}_{6} \mathrm{H}_{4}(1 \mathrm{i})$ & $3 \mathbf{i a}$ & 75 & $>20: 1$ \\
\hline & $2-\mathrm{MeC}_{6} \mathrm{H}_{4}(\mathbf{1 j})$ & $3 \mathbf{j a}$ & 79 & $>20: 1$ \\
\hline 10 & $3-\mathrm{MeC}_{6} \mathrm{H}_{4}(\mathbf{1 k})$ & $3 \mathbf{k a}$ & 76 & $>20: 1$ \\
\hline 1 & $4-\mathrm{MeC}_{6} \mathrm{H}_{4}(\mathbf{1 I})$ & 3la & 73 & $>20: 1$ \\
\hline 2 & $2-\mathrm{OMeC}_{6} \mathrm{H}_{4}(\mathbf{1 m})$ & $3 \mathrm{ma}$ & 67 & $>20: 1$ \\
\hline 3 & $3-\mathrm{OMeC}_{6} \mathrm{H}_{4}(\mathbf{1 n})$ & 3na & 75 & $>20: 1$ \\
\hline 44 & $4-\mathrm{OMeC}_{6} \mathrm{H}_{4}(\mathbf{1 0})$ & $30 a$ & 77 & $>20: 1$ \\
\hline 15 & 2-Naphthyl (1p) & 3 pa & 72 & $>20: 1$ \\
\hline 16 & 2-Thienyl (1q) & $3 q a$ & 74 & $>20: 1$ \\
\hline
\end{tabular}

${ }^{a}$ Reactions were carried out with $1(0.1 \mathrm{mmol}), 2 \mathrm{a}(0.12 \mathrm{mmol})$, and DBU $(20 \mathrm{~mol} \%)$ in $2 \mathrm{~mL}$ of THF at rt for $12-48 \mathrm{~h} .{ }^{b}$ Isolated yields. ${ }^{c}$ Determined by ${ }^{1} \mathrm{H}$ NMR.

yields. Both electron-withdrawing (entries 1-8) and electrondonating substituents (entries 9-14) on the benzene ring were tolerated and the yields of the former were slightly higher than the latter. And either para-, meta- or orthosubstituted phenyl cyclic 1 -azadienes 1 could serve as suitable reaction partners, while $1 \mathrm{~m}$ bearing ortho-methoxyphenyl gave moderate yield ( $67 \%$ yield) due to the steric hindrance (entry 12). Moreover, 2-naphthyl and 2-thienyl substituted substrates 1p and 1q exhibited good reactivities, delivering the desired products $3 \mathbf{p a}$ in $72 \%$ yield and 3qa in $74 \%$ yield, respectively (entries $15-16$ ).

Subsequently, we performed the application of cyclic 1-azadiene 1a in DBU-catalyzed [3+2] cycloaddition with a variety of 3homoacyl coumarins 2 under the optimal conditions (Table 3). And substrates 2 with electron-withdrawing (F, Cl, Br, Table 2, entries 1-5) or electron-donating (Me, MeO, entries 6-9) substituents at 6 or 7 position were all suitable for the cycloaddition, affording the cycloadducts 3aa-3ai in good to excellent yields of 78-94\%. Replacing the $\mathrm{R}^{1}$ group with $\mathrm{H}$, the desired product 3aj was obtained in $85 \%$ yield (entry 10). Notably, when the $\mathrm{R}^{2}$ were para-substituted phenyl groups, the cycloaddition reactions underwent smoothly to deliver the products 3ak-3am in up to $92 \%$ yield, and para-methyl substituted $\mathbf{2 m}$ gave a lower yield compared to para-electron-withdrawing substituted $2 \mathbf{k}$ and $2 \mathbf{l}$ (entries 11-13). The structure of product 3aj was confirmed by its X-ray crystallographic data. ${ }^{12}$ 
Table 3 Substrate scope of 3-homoacyl coumarins $2^{a}$

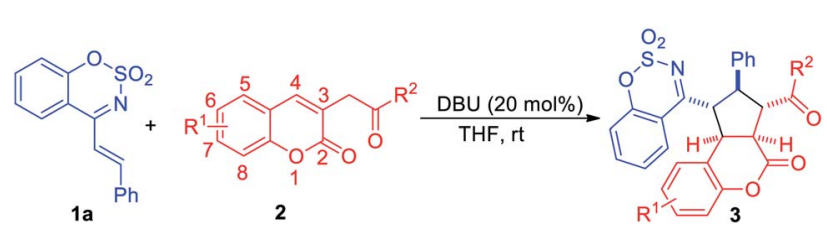

\begin{tabular}{lllll}
\hline Entry & $\mathrm{R}^{1} / \mathrm{R}^{2}$ & $\mathbf{3}$ & Yield $^{b}(\%)$ & $\mathrm{dr}^{c}$ \\
\hline 1 & $6-\mathrm{Br} / \mathrm{C}_{6} \mathrm{H}_{5}(\mathbf{2 a})$ & 3aa & 86 & $>20: 1$ \\
2 & $6-\mathrm{F} / \mathrm{C}_{6} \mathrm{H}_{5}(\mathbf{2 b})$ & $\mathbf{3 a b}$ & 88 & $>20: 1$ \\
3 & $6-\mathrm{Cl} / \mathrm{C}_{6} \mathrm{H}_{5}(\mathbf{2 c})$ & $\mathbf{3 a c}$ & 78 & $>20: 1$ \\
4 & $7-\mathrm{Cl} / \mathrm{C}_{6} \mathrm{H}_{5}(\mathbf{2 d})$ & $\mathbf{3 a d}$ & 84 & $>20: 1$ \\
5 & $7-\mathrm{Br} / \mathrm{C}_{6} \mathrm{H}_{5}(\mathbf{2 e})$ & $\mathbf{3 a e}$ & 86 & $>20: 1$ \\
6 & $6-\mathrm{Me} / \mathrm{C}_{6} \mathrm{H}_{5}(\mathbf{2 f})$ & $\mathbf{3 a f}$ & 87 & $>20: 1$ \\
7 & $6-\mathrm{OMe} / \mathrm{C}_{6} \mathrm{H}_{5}(\mathbf{2 g})$ & $\mathbf{3 a g}$ & 94 & $>20: 1$ \\
8 & $7-\mathrm{Me} / \mathrm{C}_{6} \mathrm{H}_{5}(\mathbf{2 h})$ & $\mathbf{3 a h}$ & 86 & $>20: 1$ \\
9 & $7-\mathrm{OMe} / \mathrm{C}_{6} \mathrm{H}_{5}(\mathbf{2 i})$ & $\mathbf{3 a i}$ & 83 & $>20: 1$ \\
10 & $\mathrm{H} / \mathrm{C}_{6} \mathrm{H}_{5}(\mathbf{2} \mathbf{j})$ & $\mathbf{3 a j}$ & 83 & $>20: 1$ \\
11 & $\mathrm{H} / 4-\mathrm{FC}_{6} \mathrm{H}_{4}(\mathbf{2 k})$ & 3ak & 90 & $>20: 1$ \\
12 & $\mathrm{H} / 4-\mathrm{BrC}_{6} \mathrm{H}_{4}(\mathbf{2 l})$ & 3al & 92 & $>20: 1$ \\
13 & $\mathrm{H} / 4-\mathrm{MeC}_{6} \mathrm{H}_{4}(\mathbf{2 m})$ & 3am & 80 & $>20: 1$
\end{tabular}

${ }^{a}$ Reactions were carried out with $1 \mathrm{a}(0.1 \mathrm{mmol}), 2(0.12 \mathrm{mmol})$, and DBU $(20 \mathrm{~mol} \%)$ in $2 \mathrm{~mL}$ of THF at rt for $12-48 \mathrm{~h} .{ }^{b}$ Isolated yields. ${ }^{c}$ Determined by ${ }^{1} \mathrm{H}$ NMR.

Table 4 Screening of enantioselective reaction conditions ${ }^{a}$

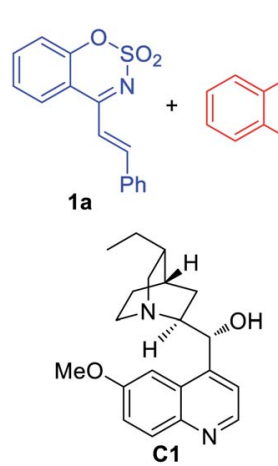

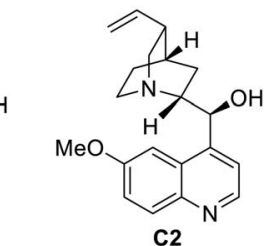

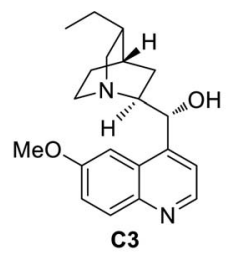<smiles>O=C1CN2CCSC2=N[C@H]1c1ccccc1</smiles><smiles>CC(C)(C)CC1CN2C[C@H](C(C)(C)C)N=C2N1</smiles>

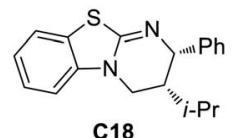

C18

\begin{tabular}{llllll}
\hline Entry & Catalyst & Time $(\mathrm{h})$ & Yield $^{b}(\%)$ & $\mathrm{dr}^{c}$ & $\mathrm{ee}^{d}(\%)$ \\
\hline 1 & C1 & 120 & 46 & $>20: 1$ & 27.3 \\
2 & C2 & 120 & 52.4 & $>20: 1$ & 9.5 \\
3 & C3 & 120 & 60 & $>20: 1$ & 8 \\
4 & C9 & 120 & 31 & $>20: 1$ & 4.5 \\
5 & C16 & 120 & 73 & $>20: 1$ & 11 \\
6 & C18 & 120 & 36 & $>20: 1$ & 11
\end{tabular}

${ }^{a}$ Reactions were carried out with $1 \mathrm{a}(0.1 \mathrm{mmol}), 2 \mathrm{j}(0.12 \mathrm{mmol})$, and $20 \mathrm{~mol} \%$ catalyst in $2 \mathrm{~mL}$ of $\mathrm{CH}_{3} \mathrm{CN}$ at rt. ${ }^{b}$ Isolated yields. ${ }^{c}$ Determined by ${ }^{1} \mathrm{H}$ NMR. ${ }^{d}$ Determined by HPLC analysis.
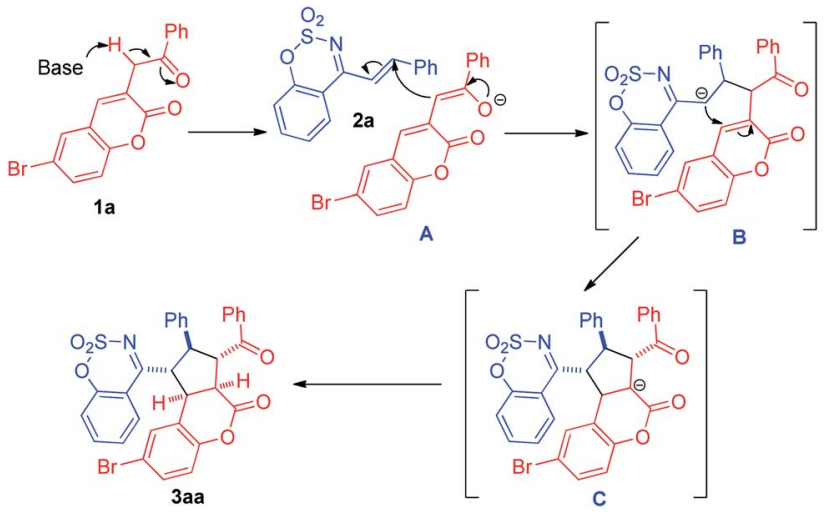

Scheme 2 Plausible reaction mechanism.
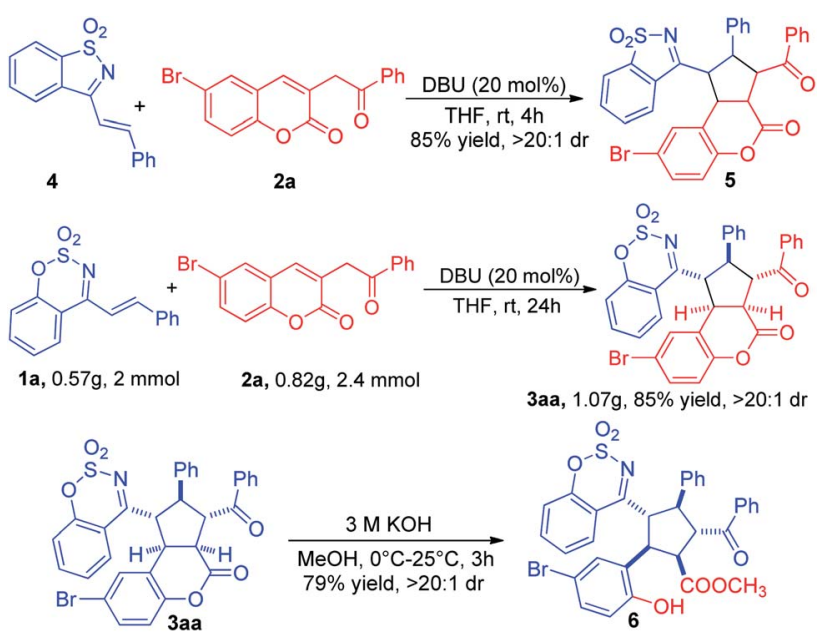

Scheme 3 [3+2] cycloaddition of 4 and $2 a$, gram-scale reaction and further transformation.

To explore the asymmetric variant of this [3+2] cycloaddition reaction of $\mathbf{1 a}$ and $\mathbf{2} \mathbf{j}$, a series of commercially available chiral amines were screened, and unfortunately, this reaction did not proceeded in $\mathrm{CH}_{2} \mathrm{Cl}_{2}$ and THF. However, when $\mathrm{CH}_{3} \mathrm{CN}$ was employed as a solvent, this reaction could be catalysed by a few of chiral amines, giving poor enantioselectivities and low to moderate yields (see ESI Table S1†). As shown in Table 3, cinchona catalyst $\mathbf{C 1}$ catalyzed the reaction to afford the 3 aj in $46 \%$ yield with the highest $27.3 \%$ ee, and the reaction could be catalyzed by diimidazole catalyst C16 to give the highest $73 \%$ yield but poor $11 \%$ ee. The subsequent attempts to find the optimal asymmetric reaction conditions failed (Table 4).

On the basis of the results and previous literature,${ }^{6}$ herein we proposed a plausible mechanism for the [3+2] cycloaddition reaction (Scheme 2), which proceeded via stepwise mechanism with zwitterion. ${ }^{13}$ Firstly, 1a is deprotonated to deliver the dienolate intermediate A under basic conditions. Subsequently, the $\alpha$-carbanion of $\mathbf{A}$ attracks the olefinic bond of $\mathbf{2} \mathbf{a}$ to form the anion B. Then through cyclization and protonation, the final $[3+2]$ cycloaddition product $\mathbf{3 a a}$ is given. 
As shown in Scheme 3, the saccharin-derived cyclic 1-azadiene 4 was tested under the optimized reaction conditions. Delightfully, the $[3+2]$ cycloadduct 5 could also be easily prepared in $85 \%$ yield and $>20: 1 \mathrm{dr}$. To explore the synthetic utility of this cycloaddition, a gram scale reaction was carried out to obtain the desired cycloadduct 3aa without any loss of yield and diastereoselectivity. The lactone of 3aa was opened under basic condition to give the multisubstituted cyclopentane 6 in $79 \%$ yield and $>20: 1 \mathrm{dr}$ (Scheme 3 ).

\section{Conclusions}

In summary, we have successfully developed a DBU catalyzed $[3+2]$ cycloaddition reaction of 3-homoacyl coumarins with cyclic 1-azadienes. The present protocol offers an efficient methodology to synthesize cyclopentane-fused coumarin derivatives with complete chemoselectivity and excellent diastereoselectivity in good yields. Efforts on further investigations of this protocol are underway in our group.

\section{Conflicts of interest}

There are no conflicts to declare.

\section{Acknowledgements}

This work was supported by the National Natural Science Foundation of China (No. 21801180), the Natural Science Foundation of Shandong Province (ZR2018LB010, ZR2019BB054), Doctoral Scientific Research Foundation of Shandong First Medical University, the Innovative Research Programs of Higher Education of Shandong Province (2019KJC009), Academic promotion programme of Shandong First Medical University (2019QL008).

\section{Notes and references}

1 (a) G. S. Clark, Perfum. Flavor., 1995, 20, 23-34; (b) D. Yu, M. Suzuki, L. Xie, S. L. Morris-Natschke and K.-H. Lee, Med. Res. Rev., 2003, 23, 322-345; (c) F. Borges, F. Roleira, N. Milhazes, L. Santana and E. Uriarte, Curr. Med. Chem., 2005, 12, 887-916; (d) A. M. Breul, M. D. Hager and U. S. Schubert, Chem. Soc. Rev., 2013, 42, 5366-5407; (e) F. G. Medina, J. G. Marrero, M. Macías-Alonso, M. C. González, I. Córdova-Guerrero, A. G. T. García and S. Osegueda-Robles, Nat. Prod. Rep., 2015, 32, 1472-1507.

2 (a) E. B. Melian and K. L. Goa, Drugs, 2002, 62, 107-133; (b) J. L. Reino, R. Durán-Patrón, I. Segura, R. HernándezGalán, H. H. Riese and I. G. Collado, J. Nat. Prod., 2003, 66, 344-349; (c) B. M. Trost and T. M. Lam, J. Am. Chem. Soc., 2012, 134, 11319-11321; (d) A. Goto, S. Yoshimura, Y. Nakao, M. Inai, T. Asakawa, M. Egi, Y. Hamashima and M. Kondo, Org. Lett., 2017, 19, 3358-3361; (e) H. P. A. Khan, D. Das and T. K. Chakraborty, J. Org. Chem., 2018, 83, 6086-6092.

3 M. McLean and M. F. Dutton, Pharmacol. Ther., 1995, 65, 163-192.
4 (a) A. Matsuo, S. Yuki and M. Nakayama, J. Chem. Soc., Perkin Trans. 1, 1986, 701-710; (b) D. Ng, Z. Yang and M. A. GarciaGaribay, Org. Lett., 2004, 6, 645-647; (c) A. Srikrishna and B. Vasantha Lakshmi, Tetrahedron Lett., 2005, 46, 4879-4881; (d) P. Kamat, S. G. Tilve, V. P. Kamat and J. K. Kirtany, Org. Prep. Proced. Int., 2015, 47, 1-79; (e) M. Michalak, K. Michalak and J. Wicha, Nat. Prod. Rep., 2017, 34, 361-410; (f) M. I. L. Soares, C. S. B. Gomes, S. C. C. Nunes, A. A. C. C. Pais and T. M. V. D. P. e. Melo, Eur. J. Org. Chem., 2019, 32, 5441-5451.

5 (a) Y. Fukuyama, H. Yuasa, Y. Tonoi, K. Harada, M. Wada, Y. Asakawa and T. Hashimoto, Tetrahedron, 2001, 57, 92999307; (b) C. E. Henry and O. Kwon, Org. Lett., 2007, 9, 3069-3072; (c) A. Marinetti, M. Neel, J. Gouin and A. Voituriez, Synthesis, 2011, 12, 2003-2009; (d) A. Bhunia, A. Patra, V. G. Puranik and A. T. Biju, Org. Lett., 2013, 15, 1756-1759; (e) Q. Liu, X.-Y. Chen, R. Puttreddy, K. Rissanen and D. Enders, Angew. Chem., Int. Ed., 2018, 57, 17100-17103.

6 (a) Y.-R. Chen, M. R. Ganapuram, K.-H. Hsieh, K.-H. Chen, P. Karanam, S. S. Vagh, Y.-C. Liou and W. Lin, Chem. Commun., 2018, 54, 12702-12705; (b) S. S. Vagh, P. Karanam, C.-C. Liao, T.-H. Lin, Y.-C. Liou, A. Edukondalu, Y.-R. Chen and W. Lin, Adv. Synth. Catal., 2020, 362, 1679-1685; (c) M. Wang, P. Y. Tseng, W. J. Chi, S. Suresh, A. Edukondalu, Y. R. Chen and W. Lin, Adv. Synth. Catal., 2020, 362, 3407-3415.

7 (a) C. Ma, J. Gu, B. Teng, Q. Zhou, R. Li and Y.-C. Chen, Org. Lett., 2013, 15, 6206-6209; (b) K.-K. Wang, T. Jin, X. Huang, Q. Ouyang, W. Du and Y.-C. Chen, Org. Lett., 2016, 18, 872875; (c) Y. Wu, Y. Liu, W. Yang, H. Liu, L. Zhou, Z. Sun and H. Guo, Adv. Synth. Catal., 2016, 358, 3517-3521; (d) L. Yu, Y. Cheng, F. Qi, R. Li and P. Li, Org. Chem. Front., 2017, 4, 1336-1340; (e) Y.-H. Chen, D.-H. Li and Y.-K. Liu, ACS Omega, 2018, 3, 16615-16625; (f) Y. Lin, Q. Wang, Y. Wu, C. Wang, H. Jia, C. Zhang, J. Huang and H. Guo, RSC Adv., 2018, 8, 40798-40803; $(g)$ Q. Zhou, B. Chen, X. Huang, Y. Zeng, W. Chu, L. He and Q. Liu, Org. Chem. Front., 2019, 6, 1891-1894. 8 (a) X. Yin, Y. Zheng, X. Feng, K. Jiang, X.-Z. Wei, N. Gao and Y.-C. Chen, Angew. Chem., Int. Ed., 2014, 53, 6245-6248; (b) X. Chen, J.-Q. Zhang, S.-J. Yin, H.-Y. Li, W.-Q. Zhou and X.-W. Wang, Org. Lett., 2015, 17, 4188-4191; (c) X.-L. He, Y.-C. Xiao, W. Du and Y.-C. Chen, Chem.-Eur. J., 2015, 21, 3443-3448.

9 (a) X. Feng, Z. Zhou, C. Ma, X. Yin, R. Li, L. Dong and Y.-C. Chen, Angew. Chem., Int. Ed., 2013, 52, 14173-14176; (b) J. Gu, C. Ma, Q.-Z. Li, W. Du and Y.-C. Chen, Org. Lett., 2014, 16, 3986-3989; (c) Q. An, J. Shen, N. Butt, D. Liu, Y. Liu and W. Zhang, Adv. Synth. Catal., 2015, 357, 36273638; (d) J. Izquierdo and M. A. Pericàs, ACS Catal., 2016, 6, 348-356; (e) Z.-Q. Liang, D.-L. Wang, C.-L. Zhang and S. Ye, Org. Biomol. Chem., 2016, 14, 6422-6425; (f) Z. Wang, H. Xu, Q. Su, P. Hu, P.-L. Shao, Y. He and Y. Lu, Org. Lett., 2017, 19, 3111-3114; (g) Z. Zhou, Z.-X. Wang, Q. Ouyang, W. Xiao, W. Du and Y.-C. Chen, Chem.-Eur. J., 2017, 23, 2945-2949; (h) X. Ren, J. Lin, X. Hu and P. Xu, Org. Chem. Front., 2019, 6, 2280-2283. 
10 (a) C. Yuan, H. Liu, Z. Gao, L. Zhou, Y. Feng, Y. Xiao and H. Guo, Org. Lett., 2015, 17, 26-29; (b) C. Yuan, L. Zhou, Z. Sun and H. Guo, RSC Adv., 2016, 6, 77931-77936; (c) C. Yuan, L. Zhou, M. Xia, Z. Sun, D. Wang and H. Guo, Org. Lett., 2016, 18, 5644-5647; (d) C. Yuan, Y. Wu, D. Wang, Z. Zhang, C. Wang, L. Zhou, C. Zhang, B. Song and H. Guo, Adv. Synth. Catal., 2018, 360, 652-658.
11 J. Yan, X. Li, Y. Chen, Y. Li, W. Chen, R. Zhan and H. Huang, J. Org. Chem., 2020, 85, 12175-12186.

12 Crystallographic data for 3aj have been deposited with the Cambridge Crystallographic Data Centre as deposition number CCDC 2073841. $\dagger$

13 R. Jasiński and E. Dresler, Organics, 2020, 1, 49-69. 